\title{
Plasma Trimethylamine-N-oxide following Cessation of L-carnitine Supplementation in Healthy Aged Women
}

\author{
Joanna J. Samulak ${ }^{1}$, Angelika K. Sawicka ${ }^{1}$, Emilia Samborowska ${ }^{2}$ and Robert A. Olek ${ }^{1, *(D)}$ \\ 1 Faculty of Rehabilitation and Kinesiology, Department of Bioenergetics and Nutrition, \\ Gdansk University Physical Education and Sport, Gorskiego 1, 80-336 Gdansk, Poland; \\ joanna.samulak@awf.gda.pl (J.J.S.); angelika.sawicka@awf.gda.pl (A.K.S.) \\ 2 Mass Spectrometry Laboratory, Institute of Biochemistry and Biophysics, Polish Academy of Sciences, \\ Pawinskiego 5a, 02-106 Warsaw, Poland; emi.sambor@gmail.com \\ * Correspondence: robert.olek@aol.com; Tel.: +48-58-554-7392
}

Received: 13 May 2019; Accepted: 11 June 2019; Published: 13 June 2019

\begin{abstract}
L-carnitine supplementation elevates plasma trimethylamine-N-oxide (TMAO), which may participate in atherosclerosis development by affecting cholesterol metabolism. The aim of the current study was to determine the effect of increased plasma TMAO on biochemical markers in the blood following cessation of L-carnitine supplementation. The follow-up measurements were performed on subjects who completed 24 weeks of L-carnitine or placebo supplementation protocol. Blood samples were taken after finishing the supplementation and then 4 and 12 months following the supplementation withdrawal. Four months after cessation of L-carnitine supplementation, plasma TMAO concentration reached a normal level which was stable for the following eight months. During this period, no modifications in serum lipid profile and circulating leukocyte count were noted. TMAO implications in health and disease is widely discussed. The results of this study demonstrate no adverse effects of elevated plasma TMAO, induced by L-carnitine, on the measured parameters at 4 and 12 months after withdrawal of supplementation.
\end{abstract}

Keywords: cardiovascular disease; endothelial dysfunction; atherosclerosis; cholesterol; leukocytes

\section{Introduction}

Atherosclerosis is a leading cause of vascular disease worldwide, even if several major modifiable risk factors have been identified [1]. The early atherosclerotic lesion is characterized by the accumulation of arterial foam cells derived mainly from cholesterol-loaded macrophages [2]. Thus, cholesterol metabolism has generated considerable notoriety for its causative role in atherosclerosis [3]. Recent studies suggest that trimethylamine N-oxide (TMAO) may participate in the development of atherosclerosis [4]. By reducing reverse cholesterol transport, TMAO elevates cholesterol uptake in the vascular wall, leading to macrophage foam cell formation and atherosclerotic lesion development $[4,5]$.

TMAO may be produced by the intestinal microbiota using L-carnitine as a substrate [5]. Therefore, L-carnitine has been suggested as a potential link between red meat consumption and atherosclerosis development [5]. L-carnitine is consumed not only from red meat but as a supplement due to its potential "fat burning" properties [6]. In fact, dietary L-carnitine supplementation induces TMAO elevation in human blood [7-10].

The aim of the current study was to determine the effect of increased plasma TMAO on biochemical markers in the blood following cessation of L-carnitine supplementation. 


\section{Materials and Methods}

\subsection{Subjects}

The follow-up measurements were performed on subjects who had completed a study evaluating the effect of L-carnitine supplementation on skeletal muscle function [11]. Due to personal reasons, follow-up measurements were discontinued by two subjects. Therefore, the results of 18 women in the age range of $65-70$ years, L-carnitine $(n=10)$ and placebo $(n=8)$, were used for statistical analyses.

\subsection{Study Procedure}

Subjects visited the laboratory after 24 weeks supplementation of either $1500 \mathrm{mg}$ L-carnitine-L-tartrate or isonitrogenous placebo per day, as described previously [11], and 4 and 12 months following the cessation of supplementation (Figure 1). The study protocol was approved by the Independent Bioethics Commission for Research at Medical University of Gdansk (NKBBN/354-304/2015 and NKBBN/354-201/2017). All subjects gave written informed consent for participation in the study.

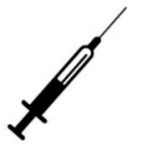

start

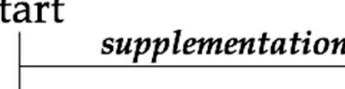

Time 0
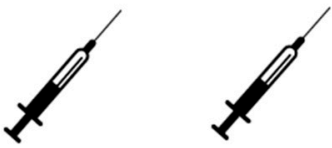

end

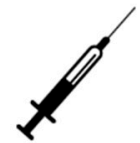

4 months

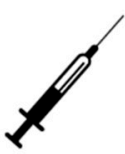

12 months

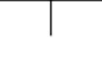

6 months

10 months

Figure 1. Study time line. Syringes indicate blood sampling. The results of the supplementation protocol have been presented elsewhere [10,11].

\subsection{Fish Consumption Habits}

Nutritional intake patterns, especially fish and seafood, have a great impact on TMAO production in the human body [12]. Therefore, to assess the frequency of fish consumption, a specific survey was constructed in a comprehensible form that was easily filled out by all subjects. The survey used quantitative research methods to identify "frequency consumption groups" [13]:

$$
\begin{aligned}
& \text { F0 - never/occasionally, } \\
& \text { F1-1-2 times per month, } \\
& \text { F2 - once per week, } \\
& \text { F3 - 2-5 times per week, } \\
& \text { F4 - every day. }
\end{aligned}
$$

\subsection{Blood Sampling}

Fasting blood samples were taken from the antecubital vein. White blood cell (WBC) count and differential leukocyte count were determined using an automated hematology analyzer (Sysmex XT 2000, Global Medical Instrumentation, Inc (Mundelein, IL, USA)) in the whole blood. Serum and EDTA-plasma were obtained by centrifugation at $2000 \times g$ at $4{ }^{\circ} \mathrm{C}$ for $10 \mathrm{~min}$. Samples were stored at $-80{ }^{\circ} \mathrm{C}$ until analyses.

\subsection{Biochemical Determination}

Plasma TMAO was determined by the UPLC/MS/MS method as described previously [14]. Total cholesterol (TCh), high-density lipoprotein (HDL) cholesterol, low-density lipoprotein (LDL) cholesterol, and triglycerides (TG) were determined using Cobas6000 (Roche Diagnostics, Mannheim, Germany). 


\subsection{Statistical Analyses}

Statistical calculations were performed using Statistica 13.1 (Dell Inc., Tulsa, OK, USA). The analysis of variance (ANOVA) for repeated measurements was performed to examine the interaction between the treatment and time, with Tukey-Kramer post hoc comparisons. A probability level of $p<0.05$ was considered statistically significant. All data are expressed as mean \pm standard error (SE).

\section{Results}

At the end of the supplementation protocol, the plasma TMAO concentration reached $33.6 \pm 6.7 \mu \mathrm{M}$ in the L-carnitine group, whereas it was $2.9 \pm 0.3 \mu \mathrm{M}$ in the placebo group (Figure 1). Four months after cessation of supplementation, plasma TMAO decreased to a level comparable to the placebo group and remained stable for the following eight months (Figure 2).

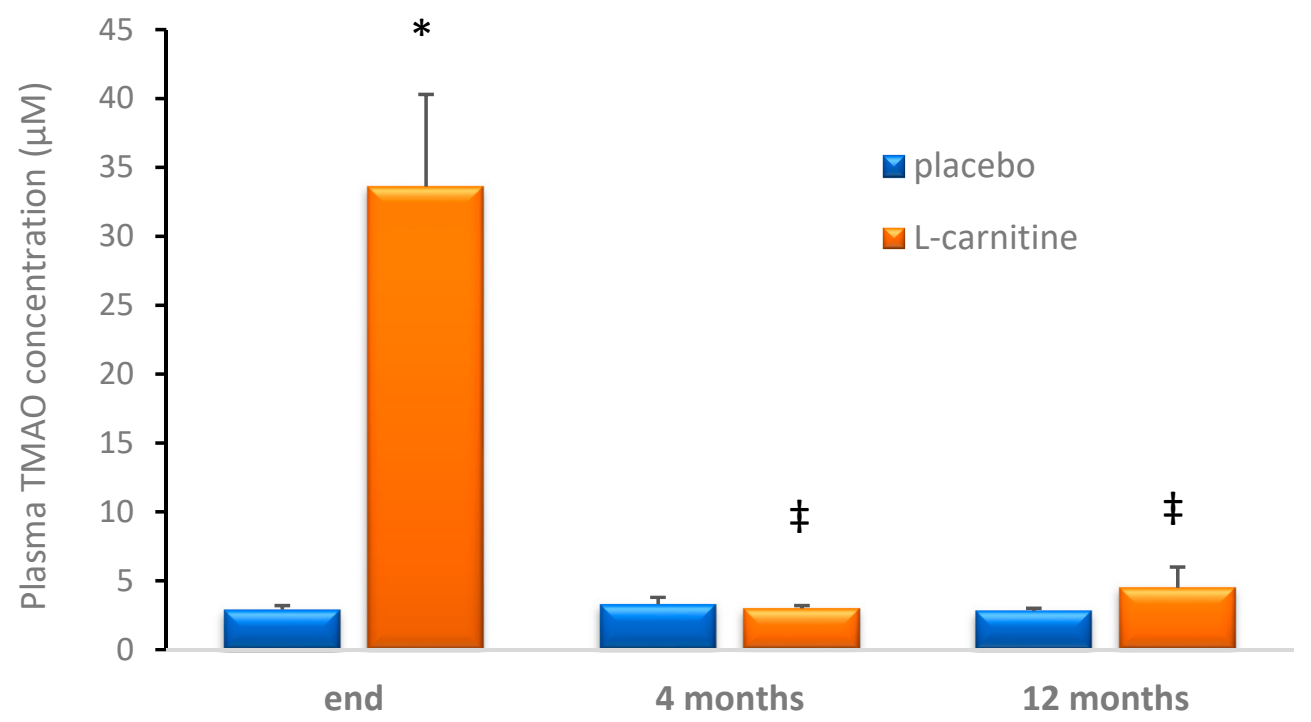

Figure 2. Plasma trimethylamine-N-oxide (TMAO) concentrations in placebo and L-carnitine groups. * $p<0.001$ as compared to placebo group at the same time point, $\ddagger p<0.001$ as compared to the end of supplementation in the same group.

During the same time intervals, circulating lipid profile metabolites were not modified by either the supplementation or the washout period (Table 1).

Table 1. Serum lipid metabolites in L-carnitine and placebo groups after 24 weeks of supplementation (end) and 4 and 12 months after cessation of supplementation.

\begin{tabular}{ccccccc}
\hline & \multicolumn{3}{c}{ L-carnitine } & Placebo \\
\hline & End & 4 Months & 12 Months & End & 4 Months & 12 Months \\
\hline TCh $\left(\mathrm{mg} \cdot \mathrm{dL}^{-1}\right)$ & $217 \pm 12$ & $213 \pm 16$ & $211 \pm 13$ & $199 \pm 15$ & $211 \pm 10$ & $202 \pm 11$ \\
HDL $\left(\mathrm{mg} \cdot \mathrm{dL}^{-1}\right)$ & $67 \pm 5$ & $72 \pm 6$ & $70 \pm 5$ & $61 \pm 4$ & $72 \pm 7$ & $67 \pm 5$ \\
LDL $\left(\mathrm{mg} \cdot \mathrm{dL}^{-1}\right)$ & $127 \pm 10$ & $119 \pm 14$ & $115 \pm 12$ & $117 \pm 13$ & $120 \pm 10$ & $117 \pm 7$ \\
TG $\left(\mathrm{mg} \cdot \mathrm{dL}^{-1}\right)$ & $114 \pm 18$ & $116 \pm 14$ & $130 \pm 22$ & $103 \pm 18$ & $98 \pm 12$ & $89 \pm 14$ \\
\hline
\end{tabular}

TCh: total cholesterol; HDL: high-density lipoprotein cholesterol; LDL: low-density lipoprotein cholesterol; TG: triglycerides.

Similarly, the leukocyte count remained unchanged and was not different between the groups (Table 2). 
Table 2. Circulating white blood cell counts in L-carnitine and placebo groups after 24 weeks of supplementation (end) and 4 and 12 months after cessation of supplementation.

\begin{tabular}{ccccccc}
\hline & \multicolumn{3}{c}{ L-carnitine } & \multicolumn{3}{c}{ Placebo } \\
\hline & End & 4 Months & 12 Months & End & 4 Months & 12 Months \\
\hline Leuko $\left(10^{9} \cdot \mathrm{L}^{-1}\right)$ & $5.7 \pm 0.5$ & $6.1 \pm 0.6$ & $6.6 \pm 0.8$ & $5.4 \pm 0.4$ & $5.7 \pm 0.5$ & $5.5 \pm 0.4$ \\
Neutro $\left(10^{9} \cdot \mathrm{L}^{-1}\right)$ & $3.0 \pm 0.3$ & $3.4 \pm 0.5$ & $3.7 \pm 0.5$ & $3.0 \pm 0.2$ & $3.0 \pm 0.4$ & $2.7 \pm 0.2$ \\
Lympho $\left(10^{9} \cdot \mathrm{L}^{-1}\right)$ & $2.0 \pm 0.2$ & $2.0 \pm 0.2$ & $2.1 \pm 0.2$ & $1.8 \pm 0.2$ & $2.1 \pm 0.2$ & $2.1 \pm 0.2$ \\
NLR & $1.6 \pm 0.2$ & $1.7 \pm 0.2$ & $1.8 \pm 0.2$ & $1.7 \pm 0.2$ & $1.5 \pm 0.2$ & $1.4 \pm 0.1$ \\
Mono $\left(10^{9} \cdot \mathrm{L}^{-1}\right)$ & $0.51 \pm 0.04$ & $0.51 \pm 0.03$ & $0.54 \pm 0.05$ & $0.45 \pm 0.06$ & $0.46 \pm 0.06$ & $0.45 \pm 0.04$ \\
Platelets $\left(10^{9} \cdot \mathrm{L}^{-1}\right)$ & $279 \pm 16$ & $272 \pm 12$ & $291 \pm 13$ & $249 \pm 19$ & $248 \pm 18$ & $253 \pm 23$ \\
\hline
\end{tabular}

Leuko: leukocytes; Neutro: neutrophils; Lympho: lymphocytes; NLR: neutrophil-to-lymphocyte ratio; Mono: monocytes.

No differences in fish consumption habits were noted (Table 3).

Table 3. The frequency of fish consumption.

\begin{tabular}{ccccc}
\hline & \multicolumn{2}{c}{ L-carnitine } & \multicolumn{2}{c}{ Placebo } \\
\hline Median & Range & Median & Range \\
\hline Cod & F1 & F0-F3 & F1 & F0-F3 \\
Malmon & F1 & F0-F2 & F2 & F0-F3 \\
Heckerel & F1 & F0-F2 & F1 & F0-F2 \\
Trout & F1 & F0-F3 & F1 & F0-F3 \\
Tuna & F0 & F0-F1 & F1 & F0-F3 \\
Flounder & F0 & F0-F1 & F0 & F0-F2 \\
Hake & F0 & F0-F1 & F0 & F0-F1 \\
Eel & F0 & F0-F1 & F0 & F0-F1 \\
Pollock & F0 & F0-F1 & F0 & F0-F1 \\
\hline
\end{tabular}

F0: never/occasionally; F1: 1-2 times per month; F2: once per week; F3: 2-5 times per week.

\section{Discussion}

The main finding of the current study is that four months after cessation of L-carnitine supplementation, plasma TMAO concentration reached a normal level which was stable for the following eight months. During this period, no modifications in serum lipid profile and circulating leukocyte count were noted.

Elevated plasma TMAO has been suggested as a predictor of poor prognosis in cardiovascular disease patients associated with increased risk of major adverse cardiovascular events or death [15-18]. However, adjustment for kidney function abolishes the statistical significance of plasma TMAO in relation to patients' mortality [18]. It is worth noting that cardiovascular disease and kidney disease are closely interrelated [19] and diminished renal function is strongly associated with morbidity and mortality in heart failure patients [20]. Moreover, at the beginning of this century, elevated plasma TMAO levels were detected in patients with chronic renal disease [21] and were suggested as a marker of ischemic kidney damage [22]. Glomerular filtration rates of the subjects participating in this study were within the normal range [10], and four months after cessation of L-carnitine treatment, TMAO decreased to a level comparable to the values observed before supplementation started [10].

Higher risks of all-cause and cardiovascular disease mortality have been linked to red meat consumption [23], with TMAO as a potential link between red meat consumption and atherosclerosis development [5]. However, in the German adult population, meat consumption was not related to plasma TMAO [24]. Moreover, a minor increase in plasma TMAO was observed following red meat and processed meat consumption, whereas fish induced significant elevation of plasma TMAO [25]. Furthermore, Veeravalli et al. [26] reported that TMAO does not increase plasma cholesterol or act as a 
proatherogenic molecule under normal dietary conditions. Levels of red meat and fish consumption of the subjects participating in this study were similar in both groups [11] and did not differ from nutritional habits in this region [13].

TMAO is produced using L-carnitine as a substrate [5]; thus, L-carnitine supplementation elevates plasma TMAO [7-10]. In patients with inborn errors of metabolism who require L-carnitine supplementation, the average plasma TMAO reached $120 \mu \mathrm{M}$, which was $\sim 45$-fold higher compared with patients without a diagnosed genetic disorder on a standard omnivorous Western diet that was not supplemented by L-carnitine [8]. Vallance et al. [9] reported that L-carnitine treatment $(1000 \mathrm{mg}$ daily for $>1$ year) of patients with mitochondrial disorders induced a $\sim 12$-fold increase in median TMAO concentration ( 3.54 vs. $43.26 \mu \mathrm{M}$ ). It is worth noting that one subject with chronic kidney disease had a marked elevation of plasma TMAO at baseline $(33.98 \mu \mathrm{M})$, which increased 3-fold on oral L-carnitine therapy (33.98 vs. $101.6 \mu \mathrm{M}$ ) [9]. Healthy aged women, participating in the current study, were supplemented by $1500 \mathrm{mg}$ L-carnitine-L-tartrate per day for 24 weeks [11]. A 10-fold increase of plasma TMAO was noted after 12 weeks of supplementation and remained elevated for the next 12 weeks [10]. Considering the increase of relative risk for all-cause mortality by $7.6 \%$ per each $10 \mu \mathrm{M}$ increment of TMAO [27], and TMAO elevation due to L-carnitine supplementation [7-10], the negative impact of L-carnitine should have been observed. However, L-carnitine has been used as a treatment for cardiovascular disease patients for decades with no detrimental effects reported (for review, see [28-30]). Even if the positive effect of L-carnitine has been recently negated, as there is no significant marginal benefit in terms of all-cause mortality, heart failure, unstable angina, or myocardial reinfarction [28], it has still not been shown to be a harmful compound-although much higher doses (e.g., $6 \mathrm{~g} /$ day for a period of 1 year) have been tested in patients with acute anterior myocardial infarction [31]. Furthermore, genetic variants of organic cation transporter 2 reduce cardiac uptake of carnitine, leading to heart failure [32].

The number of subjects examined in our study was very small. Another limitation is the relatively short period of supplementation. Since atherosclerosis develops over the course of years, 24 weeks may be not sufficient to induce any changes in the determined metabolites. However, we have noted that a 10-fold plasma TMAO increase, induced by L-carnitine supplementation, does not affect inflammatory markers (i.e., vascular cell adhesion molecule, intercellular adhesion molecule, L-selectin, P-selectin, C-reactive protein, tumor necrosis factor $\alpha$, and interleukin-6 [10]) and oxidative stress markers (unpublished). Moreover, the neutrophil-to-lymphocyte ratio (NLR), an index of systemic inflammation associated with subclinical atherosclerosis [33], during and after the supplementation remained at a level $\leq 1.8$, which was comparable to the control subjects [34]. Nevertheless, it remains unknown whether other inflammatory markers, not determined in previous studies, are influenced by carnitine supplementation.

\section{Conclusions}

TMAO implications in health and disease are widely discussed [35-37], but it is still debated whether it is a mediator in human disease development or a causative agent in the disease process [38,39].

Author Contributions: Conceptualization, R.A.O.; methodology, E.S. and R.A.O.; formal analysis, J.J.S., A.K.S., and E.S.; investigation, J.J.S., A.K.S., E.S., and R.A.O.; data curation, A.K.S. and R.A.O.; writing-original draft preparation, R.A.O.; writing-review and editing, J.J.S., A.K.S., and E.S.; supervision, R.A.O.; project administration, R.A.O.; funding acquisition, R.A.O.

Funding: This research was funded by the National Science Centre in Poland, grant number 2014/15/B/NZ7/00893. The APC was funded by DSRiK/10/2019.

Acknowledgments: The authors would like to thank the group of subjects who participated in the study.

Conflicts of Interest: The authors declare no conflict of interests. 


\section{References}

1. Herrington, W.; Lacey, B.; Sherliker, P.; Armitage, J.; Lewington, S. Epidemiology of Atherosclerosis and the Potential to Reduce the Global Burden of Atherothrombotic Disease. Circ. Res. 2016, 118, 535-546. [CrossRef]

2. Yurdagul, A., Jr.; Finney, A.C.; Woolard, M.D.; Orr, A.W. The Arterial Microenvironment: The Where and Why of Atherosclerosis. Biochem. J. 2006, 473, 1281-1295. [CrossRef]

3. Daniels, T.F.; Killinger, K.M.; Michal, J.J.; Wright, R.W., Jr.; Jiang, Z. Lipoproteins, Cholesterol Homeostasis and Cardiac Health. Int. J. Biol. Sci. 2009, 5, 474-488. [CrossRef]

4. Wang, Z.; Klipfell, E.; Bennett, B.J.; Koeth, R.; Levison, B.S.; Dugar, B.; Feldstein, A.E.; Britt, E.B.; Fu, X.; Chung, Y.M.; et al. Gut Flora Metabolism of Phosphatidylcholine Promotes Cardiovascular Disease. Nature 2011, 472, 57-63. [CrossRef]

5. Koeth, R.A.; Wang, Z.; Levison, B.S.; Buffa, J.A.; Org, E.; Sheehy, B.T.; Britt, E.B.; Fu, X.; Wu, Y.; Li, L.; et al. Intestinal Microbiota Metabolism of L-Carnitine, a Nutrient in Red Meat, Promotes Atherosclerosis. Nat. Med. 2013, 19, 576-585. [CrossRef]

6. Jakopin, Z. Risks Associated with Fat Burners: A Toxicological Perspective. Food Chem. Toxicol. 2018, 123, 205-224. [CrossRef]

7. Fukami, K.; Yamagishi, S.; Sakai, K.; Kaida, Y.; Yokoro, M.; Ueda, S.; Wada, Y.; Takeuchi, M.; Shimizu, M.; Yamazaki, H.; et al. Oral L-Carnitine Supplementation Increases Trimethylamine-N-Oxide but Reduces Markers of Vascular Injury in Hemodialysis Patients. J. Cardiovasc. Pharmacol. 2015, 65, 289-295. [CrossRef]

8. Miller, M.J.; Bostwick, B.L.; Kennedy, A.D.; Donti, T.R.; Sun, Q.; Sutton, V.R.; Elsea, S.H. Chronic Oral L-Carnitine Supplementation Drives Marked Plasma Tmao Elevations in Patients with Organic Acidemias Despite Dietary Meat Restrictions. JIMD Rep. 2016, 30, 39-44.

9. Vallance, H.D.; Koochin, A.; Branov, J.; Rosen-Heath, A.; Bosdet, T.; Wang, Z.; Hazen, S.L.; Horvath, G. Marked Elevation in Plasma Trimethylamine-N-Oxide (Tmao) in Patients with Mitochondrial Disorders Treated with Oral L-Carnitine. Mol. Genet. Metab. Rep. 2018, 15, 130-133. [CrossRef]

10. Samulak, J.J.; Sawicka, A.K.; Hartmane, D.; Grinberga, S.; Pugovics, O.; Lysiak-Szydlowska, W.; Olek, R.A. L-Carnitine Supplementation Increases Trimethylamine-N-Oxide but Not Markers of Atherosclerosis in Healthy Aged Women. Ann. Nutr. Metab. 2019, 74, 11-17. [CrossRef]

11. Sawicka, A.K.; Hartmane, D.; Lipinska, P.; Wojtowicz, E.; Lysiak-Szydlowska, W.; Olek, R.A. L-Carnitine Supplementation in Older Women. A Pilot Study on Aging Skeletal Muscle Mass and Function. Nutrients 2018, 10, 255. [CrossRef]

12. Zhang, A.Q.; Mitchell, S.C.; Smith, R.L. Dietary Precursors of Trimethylamine in Man: A Pilot Study. Food Chem. Toxicol. 1999, 37, 515-520. [CrossRef]

13. Kasielski, M.; Eusebio, M.O.; Pietruczuk, M.; Nowak, D. The Relationship between Peripheral Blood Mononuclear Cells Telomere Length and Diet-Unexpected Effect of Red Meat. Nutr. J. 2016, 15, 68. [CrossRef]

14. Jaworska, K.; Huc, T.; Samborowska, E.; Dobrowolski, L.; Bielinska, K.; Gawlak, M.; Ufnal, M. Hypertension in Rats Is Associated with an Increased Permeability of the Colon to Tma, a Gut Bacteria Metabolite. PLoS ONE 2017, 12, e0189310. [CrossRef]

15. Tang, W.H.; Wang, Z.; Levison, B.S.; Koeth, R.A.; Britt, E.B.; Fu, X.; Wu, Y.; Hazen, S.L. Intestinal Microbial Metabolism of Phosphatidylcholine and Cardiovascular Risk. N. Engl. J. Med. 2013, 368, 1575-1584. [CrossRef]

16. Tang, W.H.; Wang, Z.; Kennedy, D.J.; Wu, Y.; Buffa, J.A.; Agatisa-Boyle, B.; Li, X.S.; Levison, B.S.; Hazen, S.L. Gut Microbiota-Dependent Trimethylamine N-Oxide (Tmao) Pathway Contributes to Both Development of Renal Insufficiency and Mortality Risk in Chronic Kidney Disease. Circ. Res. 2015, 116, 448-455. [CrossRef]

17. Suzuki, T.; Heaney, L.M.; Bhandari, S.S.; Jones, D.J.; Ng, L.L. Trimethylamine N-Oxide and Prognosis in Acute Heart Failure. Heart 2016, 102, 841-848. [CrossRef]

18. Gruppen, E.G.; Garcia, E.; Connelly, M.A.; Jeyarajah, E.J.; Otvos, J.D.; Bakker, S.J.L.; Dullaart, R.P.F. Tmao Is Associated with Mortality: Impact of Modestly Impaired Renal Function. Sci. Rep. 2017, 7, 13781. [CrossRef]

19. Gansevoort, R.T.; Correa-Rotter, R.; Hemmelgarn, B.R.; Jafar, T.H.; Heerspink, H.J.; Mann, J.F.; Matsushita, K.; Wen, C.P. Chronic Kidney Disease and Cardiovascular Risk: Epidemiology, Mechanisms, and Prevention. Lancet 2013, 382, 339-352. [CrossRef] 
20. Damman, K.; Valente, M.A.; Voors, A.A.; O'Connor, C.M.; van Veldhuisen, D.J.; Hillege, H.L. Renal Impairment, Worsening Renal Function, and Outcome in Patients with Heart Failure: An Updated Meta-Analysis. Eur. Heart J. 2017, 35, 455-469. [CrossRef]

21. Bain, M.A.; Faull, R.; Fornasini, G.; Milne, R.W.; Evans, A.M. Accumulation of Trimethylamine and Trimethylamine-N-Oxide in End-Stage Renal Disease Patients Undergoing Haemodialysis. Nephrol. Dial. Transplant. 2006, 21, 1300-1304. [CrossRef]

22. Hauet, T.; Baumert, H.; Gibelin, H.; Godart, C.; Carretier, M.; Eugene, M. Citrate, Acetate and Renal Medullary Osmolyte Excretion in Urine as Predictor of Renal Changes after Cold Ischaemia and Transplantation. Clin. Chem. Lab. Med. 2000, 38, 1093-1098. [CrossRef]

23. Alshahrani, S.M.; Fraser, G.E.; Sabate, J.; Knutsen, R.; Shavlik, D.; Mashchak, A.; Lloren, J.I.; Orlich, M.J. Red and Processed Meat and Mortality in a Low Meat Intake Population. Nutrients 2019, 11, 622. [CrossRef]

24. Rohrmann, S.; Linseisen, J.; Allenspach, M.; von Eckardstein, A.; Muller, D. Plasma Concentrations of Trimethylamine-N-Oxide Are Directly Associated with Dairy Food Consumption and Low-Grade Inflammation in a German Adult Population. J. Nutr. 2016, 146, 283-289. [CrossRef]

25. Cheung, W.; Keski-Rahkonen, P.; Assi, N.; Ferrari, P.; Freisling, H.; Rinaldi, S.; Slimani, N.; Zamora-Ros, R.; Rundle, M.; Frost, G.; et al. A Metabolomic Study of Biomarkers of Meat and Fish Intake. Am. J. Clin. Nutr. 2017, 105, 600-608. [CrossRef]

26. Veeravalli, S.; Karu, K.; Scott, F.; Fennema, D.; Phillips, I.R.; Shephard, E.A. Effect of Flavin-Containing Monooxygenase Genotype, Mouse Strain, and Gender on Trimethylamine N-Oxide Production, Plasma Cholesterol Concentration, and an Index of Atherosclerosis. Drug Metab. Dispos. 2018, 46, 20-25. [CrossRef]

27. Schiattarella, G.G.; Sannino, A.; Toscano, E.; Giugliano, G.; Gargiulo, G.; Franzone, A.; Trimarco, B.; Esposito, G.; Perrino, C. Gut Microbe-Generated Metabolite Trimethylamine-N-Oxide as Cardiovascular Risk Biomarker: A Systematic Review and Dose-Response Meta-Analysis. Eur. Heart J. 2017, 38, 2948-2956. [CrossRef]

28. Shang, R.; Sun, Z.; Li, H. Effective Dosing of L-Carnitine in the Secondary Prevention of Cardiovascular Disease: A Systematic Review and Meta-Analysis. BMC Cardiovasc. Disord. 2014, 14, 88. [CrossRef]

29. Song, X.; Qu, H.; Yang, Z.; Rong, J.; Cai, W.; Zhou, H. Efficacy and Safety of L-Carnitine Treatment for Chronic Heart Failure: A Meta-Analysis of Randomized Controlled Trials. BioMed Res. Int. 2017, 2017, 6274854. [CrossRef]

30. Wang, Z.Y.; Liu, Y.Y.; Liu, G.H.; Lu, H.B.; Mao, C.Y. L-Carnitine and Heart Disease. Life Sci. 2018, 194, 88-97. [CrossRef]

31. Iliceto, S.; Scrutinio, D.; Bruzzi, P.; D'Ambrosio, G.; Boni, L.; di Biase, M.; Biasco, G.; Hugenholtz, P.G.; Rizzon, P. Effects of L-Carnitine Administration on Left Ventricular Remodeling after Acute Anterior Myocardial Infarction: The L-Carnitine Ecocardiografia Digitalizzata Infarto Miocardico (Cedim) Trial. J. Am. Coll. Cardiol. 1995, 26, 380-387. [CrossRef]

32. Grube, M.; Ameling, S.; Noutsias, M.; Köck, K.; Triebel, I.; Bonitz, K.; Meissner, K.; Jedlitschky, G.; Herda, L.R.; Reinthaler, M.; et al. Selective regulation of cardiac organic cation transporter novel type 2 (OCTN2) in dilated cardiomyopathy. Am. J. Pathol. 2011, 178, 2547-2559. [CrossRef] [PubMed]

33. Acet, H.; Ertas, F.; Akil, M.A.; Oylumlu, M.; Polat, N.; Yildiz, A.; Bilik, M.Z.; Yuksel, M.; Kaya, Z.; Ulgen, M.S. New Inflammatory Predictors for Non-Valvular Atrial Fibrillation: Echocardiographic Epicardial Fat Thickness and Neutrophil to Lymphocyte Ratio. Int. J. Cardiovasc. Imaging 2014, 30, 81-89. [CrossRef] [PubMed]

34. Demirkol, S.; Balta, S.; Unlu, M.; Arslan, Z.; Cakar, M.; Kucuk, U.; Celik, T.; Arslan, E.; Turker, T.; Iyisoy, A.; et al. Neutrophils/Lymphocytes Ratio in Patients with Cardiac Syndrome X and Its Association with Carotid Intima-Media Thickness. Clin. Appl. Thromb. Hemost. 2014, 20, 250-255. [CrossRef] [PubMed]

35. Ussher, J.R.; Lopaschuk, G.D.; Arduini, A. Gut Microbiota Metabolism of L-Carnitine and Cardiovascular Risk. Atherosclerosis 2013, 231, 456-461. [CrossRef] [PubMed]

36. Castillo-Rodriguez, E.; Fernandez-Prado, R.; Esteras, R.; Perez-Gomez, M.V.; Gracia-Iguacel, C.; Fernandez-Fernandez, B.; Kanbay, M.; Tejedor, A.; Lazaro, A.; Ruiz-Ortega, M.; et al. Impact of Altered Intestinal Microbiota on Chronic Kidney Disease Progression. Toxins 2018, 10, 300. [CrossRef] [PubMed] 
37. Fernandez-Prado, R.; Esteras, R.; Perez-Gomez, M.V.; Gracia-Iguacel, C.; Gonzalez-Parra, E.; Sanz, A.B.; Ortiz, A.; Sanchez-Nino, M.D. Nutrients Turned into Toxins: Microbiota Modulation of Nutrient Properties in Chronic Kidney Disease. Nutrients 2017, 9, 489. [CrossRef] [PubMed]

38. Nowinski, A.; Ufnal, M. Trimethylamine N-Oxide: A Harmful, Protective or Diagnostic Marker in Lifestyle Diseases? Nutrition 2018, 46, 7-12. [CrossRef]

39. Janeiro, M.H.; Ramirez, M.J.; Milagro, F.I.; Martinez, J.A.; Solas, M. Implication of Trimethylamine N-Oxide (Tmao) in Disease: Potential Biomarker or New Therapeutic Target. Nutrients 2018, 10, 1398. [CrossRef]

(C) 2019 by the authors. Licensee MDPI, Basel, Switzerland. This article is an open access article distributed under the terms and conditions of the Creative Commons Attribution (CC BY) license (http://creativecommons.org/licenses/by/4.0/). 